\title{
Judge a man by his questions rather than his answers
}

\author{
Benny Weksler, MD
}

From the Department of Surgery, University of Tennessee Health Science Center, Memphis, Tenn.

Disclosures: Author has nothing to disclose with regard to commercial support.

Received for publication Aug 21, 2015; accepted for publication Aug 21, 2015; available ahead of print Sept 22, 2015 .

Address for reprints: Benny Weksler, MD, Department of Surgery, University of Tennessee Health Science Center, 1325 Eastmoreland Ave, Ste 460, Memphis, TN 38104 (E-mail: bweksler@uthsc.edu).

J Thorac Cardiovasc Surg 2016;151:58-9

$0022-5223 / \$ 36.00$

Copyright $(2) 2016$ by The American Association for Thoracic Surgery

http://dx.doi.org/10.1016/j.jtcvs.2015.08.089

Voltaire said that one should judge a man by his questions rather than his answers. In science, the questions we ask can be more important than the answers we obtain, and often pave the way for the answers we need. This is particularly true when studying rare diseases such as thymoma. There are few prospective trials in patients with thymoma and even fewer randomized trials. Our knowledge is often dependent on small cohorts from single institutions or large collaborative databases. In this issue of the Journal, Leuzzi and colleagues ${ }^{1}$ review a large cohort of patients with stage III thymoma using the European Society of Thoracic Surgeons database, a large and robust data repository, in a study that raises many important questions.

Stage III thymomas comprise $18 \%$ to $20 \%$ of all thymoma cases. ${ }^{2}$ Approximately $30 \%$ of patients will develop recurrence, most commonly in the mediastinum or pleura. ${ }^{3,4}$ This pattern of failure has encouraged the use of adjuvant therapy, often targeting the tumor bed, in an attempt to reduce locoregional recurrence. Unfortunately, no clear conclusions can be drawn regarding the effectiveness of adjuvant therapy in stage III thymoma. Curran and colleagues ${ }^{5}$ were able to decrease local recurrence of stage III thymoma with adjuvant radiation therapy, but other investigators could not reproduce these findings. ${ }^{2,6}$ In a meta-analysis by Korst and colleagues, ${ }^{7}$ adjuvant radiation therapy was not shown to be effective in reducing recurrence of stage III thymoma. Surveillance, Epidemiology, and End Results database studies have also yielded mixed results with 1 study showing no effect and another showing improvement in cancer-specific survival. $^{8,9}$

In their current study, Leuzzi and colleagues ${ }^{1}$ review 370 patients with stage III thymoma using the European Society of Thoracic Surgeons database. The recurrence rate was $20 \%$ at 5 years and $28.5 \%$ at 10 years. In multivariate analysis, complete resection and adjuvant therapy were independent predictors of overall and cancer-specific survival. The authors also retrospectively classified the tumors according to the International Thymic Malignancy

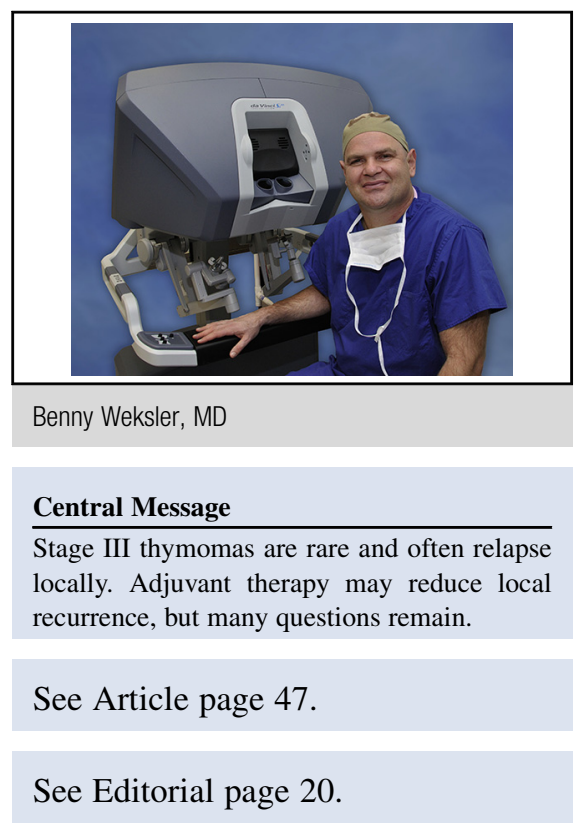

Interest Group staging proposal. ${ }^{10}$ The T stage of tumors was the only predictor of tumor relapse after therapy. To account for the retrospective nature of the data and to better control the cohort, the authors used 7 covariates, including administration of neoadjuvant therapy, to select 34 matched pairs of patients who received adjuvant therapy and patients who did not. In this matched cohort, adjuvant therapy was again shown to be an independent predictor of overall and cancer-specific survival. The strengths of this study are the large number of patients, the care with which the data were collected, and the review of tumor pathology. However, this diverse group of patients was treated using several different treatment strategies that included neoadjuvant therapy (with chemotherapy, radiotherapy, or both), surgery alone, surgery and adjuvant therapy (with chemotherapy, radiotherapy, or both), and neoadjuvant therapy followed by surgery followed by adjuvant therapy.

Because of the multitude of treatment strategies, the results are hard to interpret. Patients receiving neoadjuvant or adjuvant therapy may have received chemotherapy, radiotherapy, or both; and then there are the multiple combinations of neoadjuvant therapy, surgery, and adjuvant therapy. It is impossible to identify the 1 treatment strategy that actually affected survival. Was it the adjuvant chemotherapy or the adjuvant radiation? Or perhaps, it was the combination....

As in many large database studies, there are findings that are hard to explain and appear contradictory. For example, 
tumors larger than $5 \mathrm{~cm}$ had higher local relapse rates than tumors smaller than $5 \mathrm{~cm}$. However, adjuvant therapy (typically radiation directed at the tumor bed) did not affect survival in patients with tumors larger than $5 \mathrm{~cm}$, but did improve survival in patients with tumors smaller than $5 \mathrm{~cm}$. Is it possible that the influence of adjuvant therapy was actually in the patients who received chemotherapy instead of radiation? Patients who received neoadjuvant therapy had more aggressive tumors and higher rates of incomplete resection but their cancer-specific survival was not different than patients who did not receive neoadjuvant therapy and had a higher rate of complete resection. Does this mean that neoadjuvant therapy is not effective, or is it possible that the neoadjuvant therapy was effective in downstaging and controlling more aggressive tumors and actually improved the survival of patients with a poor initial prognosis?

This work by Leuzzi and colleagues ${ }^{1}$ gives us many more questions than answers and does not provide surgeons with clear-cut guidelines on how to treat their next patient with stage III thymoma. However, in view of this data, it appears prudent to recommend at least adjuvant radiation for patients with stage III thymoma after surgical resection. Moreover, it is time for surgeons interested in thymoma to unite with the International Thymic Malignancy Interest Group and attempt to answer some of the important questions raised by the work of Leuzzi and colleagues ${ }^{1}$ through collaborative, cross-border, prospective trials.

\section{References}

1. Leuzzi G, Rocco G, Ruffini E, Sperduti I, Detterbeck F, Weder W, et al. Multimodality Therapy for locally advanced thymomas: A propensity scorematched cohort study from the European Society of Thoracic Surgeons Database. J Thorac Cardiovasc Surg. 2016;151:47-57.e1.

2. Kondo K, Monden Y. Therapy for thymic epithelial tumors: a clinical study of 1,320 patients from Japan. Ann Thorac Surg. 2003;76:878-84; discussion 84-5.

3. Ruffini E, Mancuso M, Oliaro A, Casadio C, Cavallo A, Cianci R, et al Recurrence of thymoma: analysis of clinicopathologic features, treatment, and outcome. J Thorac Cardiovasc Surg. 1997;113:55-63.

4. Myojin M, Choi NC, Wright CD, Wain JC, Harris N, Hug EB, et al. Stage III thymoma: pattern of failure after surgery and postoperative radiotherapy and its implication for future study. Int J Radiation Oncol Biol Physics. 2000;46:927-33.

5. Curran WJ Jr, Kornstein MJ, Brooks JJ, Turrisi AT III. Invasive thymoma: the role of mediastinal irradiation following complete or incomplete surgical resection. J Clin Oncol. 1988;6:1722-7.

6. Mangi AA, Wright CD, Allan JS, Wain JC, Donahue DM, Grillo HC, et al. Adjuvant radiation therapy for stage II thymoma. Ann Thorac Surg. 2002;74:1033-7.

7. Korst RJ, Kansler AL, Christos PJ, Mandal S. Adjuvant radiotherapy for thymic epithelial tumors: a systematic review and meta-analysis. Ann Thorac Surg. 2009;87:1641-7.

8. Fernandes AT, Shinohara ET, Guo M, Mitra N, Wilson LD, Rengan R, et al. The role of radiation therapy in malignant thymoma: a Surveillance, Epidemiology, and End Results database analysis. J Thorac Oncol. 2010;5:1454-60.

9. Weksler B, Shende M, Nason KS, Gallagher A, Ferson PF, Pennathur A. The role of adjuvant radiation therapy for resected stage III thymoma: a population-based study. Ann Thorac Surg. 2012;93:1822-8; discussion 8-9.

10. Nicholson AG, Detterbeck FC, Marino M, Kim J, Stratton K, Giroux D, et al. The IASLC/ITMIG Thymic Epithelial TUmors Staging Project: Proposals for the T Component for the Forthcoming (8th) Edition of the TNM Classification of Malignant Tumors. J Thorac Oncol. 2014;9:S73-80. 